Pak. j. sci. ind. res. Ser. A: phys. sci. 2019 62A(3) 135-145

\title{
Chromium (VI) Ion Adsorption onto Maleic Acid Red Onion Skin Extract Resin (MRER) in Aqueous Solution
}

\author{
Chibuike Onyeogulu* and Millicent Uzoamaka Ibezim-Ezeani \\ Department of Pure and Industrial Chemistry, University of Port Harcourt, P.M.B.5323, Choba, Port Harcourt, \\ Nigeria
}

(received June 27, 2018; revised November 29, 2018; accepted December 4, 2018)

\begin{abstract}
Feasibility studies on the thermodynamics of $\mathrm{Cr}$ (VI) ions adsorption in aqueous medium by maleic acid red onion skin extract resin (MRER) was undertaken. The acetone extract of red onion skin was used in the synthesis of MRER. The regression analysis of the models at different temperatures and concentrations was found to closely fit the experimental data in the order: Freundlich > Langmuir > Temkin. Investigation of the thermodynamics of adsorption reaction revealed values for the change in enthalpy $(-34.05414 \mathrm{~kJ} / \mathrm{mol})$, Gibbs free energy $(-18.001,-17.362,-17.860,-15.809$ and $-16.154 \mathrm{~kJ} / \mathrm{mol})$ and entropy $(-52.7839 \mathrm{~J} / \mathrm{K} / \mathrm{mol})$, which reflected the process spontaneity, exothermic nature and feasible affinity of the interacting metal ions at the adsorption sites. Dubinin-Radushkevich (DR) isotherm was applied in studying the sorption pathway, and it was observed that physisorption is the dominant pathway. Kinetic study showed that pseudo-second order best describe the experimental data with respect to its highest correlation coefficient $\left(\mathrm{R}^{2}\right)$ values.
\end{abstract}

Keywords: maleic acid, adsorption capacity, chromium (VI) ion, Freundlich isotherm, pseudo-second order, Allium cepa

\section{Introduction}

Allium cepa (globally called onion) is cultivated worldwide. It is regarded as one of the oldest and most frequently cultivated edible plant and among one of the richest source of phenols and flavonoids (Slimestad et al., 2007). A. cepa is a vegetable with long history of medicinal use. The fleshy bulb which grows below the ground (usually used as spice) and other parts of the plant have found importance in traditional medicine (Downes et al., 2010; Abayomi and Terry, 2009). A. cepa generates large quantities of waste (for example, 450,000 tonnes of onion is generated yearly in European Union) which necessitated its management (Salak et al., 2013). Its waste evolves pungent smell and enhances the growth of phytopathogen; thus it cannot be used for fodder and land fill disposal (Roldan et al., 2008). However, it contains large moisture content, thus making it disposal by combustion expensive (Salak et al., 2013). Oancea et al. (2013) and Hwang et al. (2008) worked on the peel of A. серa and the results of their study showed that it contains large amount of flavonols, flavones and anthocyanidins. Quercetin is the common flavonol aglycone but it usually exists as glycosides, quercetin3,4-diglucoside and quercetin-4-glucoside (most

*Author for correspondence;

E-mail: onyeoguluchibuike@gmail.com abundant making up to $80-85 \%$ of the total flavonoid) (Lindahl et al., 2013).

Heavy metals are chemical elements that possess a relatively high density (Bailey et al., 1999). Presence of these metallic elements in undesirable forms in the environment is known as heavy metal pollution (Bose and Hemantaranjan, 2005). Heavy metals are toxic to living organisms at excessive concentrations, density greater than $5 \mathrm{~g} / \mathrm{cm}^{3}$ and atomic weight higher than 23 in their elemental form (Bose and Hemantaranjan, 2005). Most of the heavy metals are known to be toxic and half of these, including chromium, cadmium, silver, zinc, selenium, nickel, mercury, lead, copper and cobalt are released into the environment in quantities that pose risk to human health (Misra and Mani, 2009).

Heavy metal contamination exist in aqueous waste streams from diverse industries such as metal plating manufacturing, batteries, as well as agricultural sources where fertilizers and fungicidal sprays are intensively used. Pollution of marine ecosystem and terrestrial surroundings by heavy metals has escalated, resulting to some of the world's environmental and public health problems. This is due to the fact that these metals are persistent, very difficult to break down into smaller biodegradable fractions and bio-accumulate (Ralkwar et al., 2008). Heavy metals are non-biodegradable, thus 
builds up in important organs when ingested and get accumulated through the food web leading to poisoning of the living organisms (Cha et al., 1997).

Chromium belongs to the group of refractory metals, which comprises all metals with a higher melting point than platinum $\left(1,772^{\circ} \mathrm{C}\right)$. Naturally occurring chromium is composed of three stable isotopes ${ }^{52} \mathrm{Cr},{ }^{53} \mathrm{Cr}$ and ${ }^{54} \mathrm{Cr}$ with ${ }^{52} \mathrm{Cr}$ being the most abundant $(83.8 \%)$. Chromium is mined as chromite, $\mathrm{FeCr}_{2} \mathrm{O}_{4}$, the single commercially viable ore. Chromium exhibits a wide range of oxidation states from -4 to +6 , where +3 state is the most stable energetically. The +3 and +6 states are most commonly observed in chromium compounds. The main field of application of chromium is Ferrochrome with $95.2 \%$. Other applications have only low-volume uses: foundry $2.4 \%$, chemicals $1.6 \%$, refractory $0.8 \%$. Water-insoluble $\mathrm{Cr}$ (III) compounds and chromium metal are not considered a health hazard, while the toxicity and carcinogenic properties of $\mathrm{Cr}$ (VI) have been known for a long time. $\mathrm{Cr}$ (VI) has not been established as a carcinogen when in solution, although it may cause allergic contact dermatitis (ACD). Cr (VI) compounds are widely-used in industrial chemicals and are recognized human carcinogens. Chronic occupational exposure to hexavalent chromium causes DNA damage, respiratory diseases and lung cancer in electroplating workers (Misra and Mani, 2009).

The reduction of the pollutants to an acceptable level is necessary when toxic metals are present in aquatic systems. Methods have been introduced for elimination of these metals from aqueous media which include chemical precipitation, ion exchange, electrodialysis, solvent extractions, coagulation, evaporation and adsorption (Mohamadi et al., 2015; Garba and Afidah, 2014; Garba et al., 2014, Mohan et al., 2008). Adsorption method has been considered the most flexible and easy for removing heavy metals from waste waters (Garba et al., 2015; Cao et al., 2014) due to much less sludge disposal problems.

In recent years, special attention has been focused on the use of natural adsorbents as an alternative to replace the convectional adsorbents, from environmental and the economical point of view. Different adsorbents were described in the past for uptake of heavy metal ion; however new adsorbents with great availability, high adsorption capacity as well as economic suitability are still required. Chemically synthesized plant waste, as well as its extracts have been studied as adsorbent for heavy metal elimination; some of which include: peanut and walnut shells (Johns et al., 1998), pineapple peel (Mohammed, 2014), pomegranate peel (Masoud, 2013), rice straw (Gao et al., 2008), rice husk (Kumar and Bandopadhayay, 2006), maple sawdust (Yu et al., 2001), soybean hull (Marshall and Wartellely, 2003), corn cob (Nada et al., 2009), flax and cotton fibre (Marshall et al., 2007), orange mesocarp (Ibezim-Ezeani 2012; Ogali et al., 2008), cellulose (Thanh and Nhung, 2009), plantain peel (Zaharaddeen et al., 2016), banana peel, orange peel, maize tassel, onion and garlic skins (IbezimEzeani and Ikodiya, 2017; Kumara, 2013; Avisha et al., 2012; Zvinowanda et al., 2009).

This research is aimed to evaluate the effectiveness and capacity of modified red onion skin extract for the uptake of chromium (VI) metal ions from aqueous medium through adsorption of ions, thus producing low cost resin that is green chemistry oriented.

\section{Materials and Methods}

Sample collection and preparation. The onion skin was collected at mile 1 market in Port Harcourt, Rivers State, Nigeria. The samples were preserved in a clean plastic bag which was then transported to the laboratory for the research. The onion skin was hand sorted and washed with distilled water to remove debris. The sample was aired for three days at $29{ }^{\circ} \mathrm{C}$ to dry. The dried red onion skin was crushed into a fine powder with an electric milling machine, sieved to $150 \mu \mathrm{m}$ particles sizes and stored in an airtight bottle prior to extraction process at $29^{\circ} \mathrm{C}$.

Extraction procedure. Extraction of pulverized red onion skin $(235 \mathrm{~kg})$ was carried out using Soxhlet extractor and acetone as the extracting solvent. The desired extract was recovered from the extract-solvent mixture using a rotatory evaporator.

Preparation of maleic acid red onion skin extract resin (MRER). Red onion skin extract (15 g) was placed in $100 \mathrm{~mL}$ of deionized water at $29{ }^{\circ} \mathrm{C}$ on magnetic hot plate stirrer for $30 \mathrm{~min}$. Maleic acid (2.88 g) was added to the stirred mixture and the temperature of the mixture raised to $50{ }^{\circ} \mathrm{C}$. Iodine $(0.75 \mathrm{~g})$ was introduced into the mixture and heating continued with the temperature of the water bath maintained at $50{ }^{\circ} \mathrm{C}$ for $2 \mathrm{~h}$ (Ikodiya et al., 2016). The reaction system was then removed from the heating source and allowed to cool to $29^{\circ} \mathrm{C}$. A saturated solution of $30 \mathrm{~mL}$ sodium thiosulphate was added to the mixture and the brownish 
colour of the iodine disappeared. The mixture was filtered and the residue washed with deionized water (100 $\mathrm{mL}$, thrice). The resulting residue was oven dried for $4 \mathrm{~h}$ at $60^{\circ} \mathrm{C}$ and preserved in an air tight container at $29{ }^{\circ} \mathrm{C}$.

Adsorption capacity studies. Adsorption studies were carried out in batch equilibrium experiments to determine the adsorption capacity, effects of temperature, time and $\mathrm{pH}$ on the adsorption reaction. The experiment involves shaking $0.2 \mathrm{~g}$ of MRER in $20 \mathrm{~mL}$ of $60 \mathrm{mg} / \mathrm{L}$ of $\mathrm{Cr}$ (VI) ion solution in a mechanical shaker at 100 rpm with corked plastic bottle at $29^{\circ} \mathrm{C}$. The mixture was equilibrated for an hour and filtered with Whatman No.1 filterpaper.The filtrate was analysed with AAS (700 series) to ascertain the amount of metal ion adsorbed by MRER. The above experiment was repeated at agitation time (10 to 60 mins) and temperature (29 to $\left.70{ }^{\circ} \mathrm{C}\right)$.

The effect of $\mathrm{pH}$ on the metal ion adsorbed was resolved by placing $0.2 \mathrm{~g}$ of MRER in $20 \mathrm{~mL}$ of $60 \mathrm{mg} / \mathrm{L} \mathrm{Cr}$ (VI) ion solution at varied $\mathrm{pH}$ values $(2,4,6,8,10$ and 12). The adjustment of the $\mathrm{pH}$ was done by adding drops of $0.1 \mathrm{M} \mathrm{HCl}$ or $\mathrm{NaOH}$ into the metal solution. The solution in the corked plastic bottles were equilibrated at $29^{\circ} \mathrm{C}$ for an hour and then filtered. The metal ion concentration in the filtrate was evaluated using AAS and the percentage ion adsorbed determined.

Analysis of metal ion adsorption capacity. The percentage amount of metal ion adsorbed was obtained by the difference between the initial metal ion concentration and that of the supernatant. Percentage $\mathrm{Cr}$ (VI) ion adsorbed by MRER was calculated using the following by equation.

$$
\text { Metal ion adsorbed }(\%)=100 \times\left(\frac{\mathrm{C}_{0}-\mathrm{C}_{\mathrm{e}}}{\mathrm{C}_{\mathrm{o}}}\right) \ldots \ldots \ldots \ldots . . .1
$$

The adsorption capacity $\left(\mathrm{q}_{\mathrm{e}}\right)$ of MRER was ascertained by the mass balance from initial to equilibrium composition using the relationship in equation (2) and the values plotted against those of initial metal ion concentration.

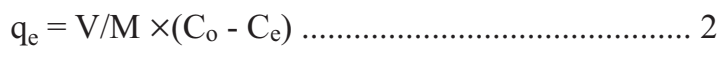

where:

$\mathrm{C}_{\mathrm{o}}$ and $\mathrm{C}_{\mathrm{e}}$ are the initial and final equilibrium metal ion concentration in solution $(\mathrm{mg} / \mathrm{L})$, respectively; $\mathrm{V}$ is the volume of the initial metal ion solution (L) and $\mathrm{m}$ is mass of MRER used (g).

Instrumentation: Scanning electron microscope (SEM coater model Q15ORES) was used to determine the morphology of the onion skin extract and that of the maleic acid red onion skin extract resin (MRER).

\section{Results and Discussion}

Adsorption studies. Effect of pH: Successful uptake of heavy metals in aqueous media relies on the establishment of a suitable $\mathrm{pH}$ range. The rate at which ions are adsorbed depends on the $\mathrm{pH}$ value of the media which directly influences the surface charge of adsorbing material, concentration of the metal ions on the active groups of the adsorbing material, rate of ionization and speciation of metal ions (Kannan and Murugavel, 2007).

The effect of $\mathrm{pH}$ on the metal ion adsorption with MRER is presented in Fig. 1. It was observed that at $\mathrm{pH}$ value of 2 , the percentage metal ion adsorbed was $73.02 \%$ and this drastically increased to $98.25 \%$ at $\mathrm{pH}$ of 4. $\mathrm{pH}$ value of 4, 6 and 8 gave similar percentage ion adsorption of $98.25,98.62$ and $98.98 \%$, respectively, while $\mathrm{pH} 10$ gave the highest percentage metal ion adsorption of $99.97 \%$ (optimum $\mathrm{pH}$ ). This suggests that the rate of metal ion adsorption would depend on the relative concentration of the exchangeable hydrogen, as well as the hydrogen ion concentration of the medium (Igwe et al., 2005). From the experimental results, it suggest that protons occupy almost all the active points at low $\mathrm{pH}$ value, thereby preventing the attraction of the metal ions to these points which in effect led to relatively lower percentage of metal ion adsorption. However, there might also be the possibility of competition between the protons and $\mathrm{Cr}$ (VI) ions resulting in lower adsorption of $\mathrm{Cr}$ (VI) ions (Hamead and Ahmand, 2009).

At high $\mathrm{pH}$ values of solution, there is a reduction in hydrogen (proton) concentration at the active points, causing the active points to be negatively charged as a result of the occurrence of hydroxide ions in the medium. This effect led to an increase in electrostatic interaction between the active points and the metal ions, thus favoring greater percentage of metal ion adsorption. Furthermore, when metal is in solution, it possesses a positive charge and will be attracted to the active point that is negatively charged at high $\mathrm{pH}$, favoring metal ion adsorption. An increase in adsorption of metals with increase in $\mathrm{pH}$ values of solution was recorded in the 


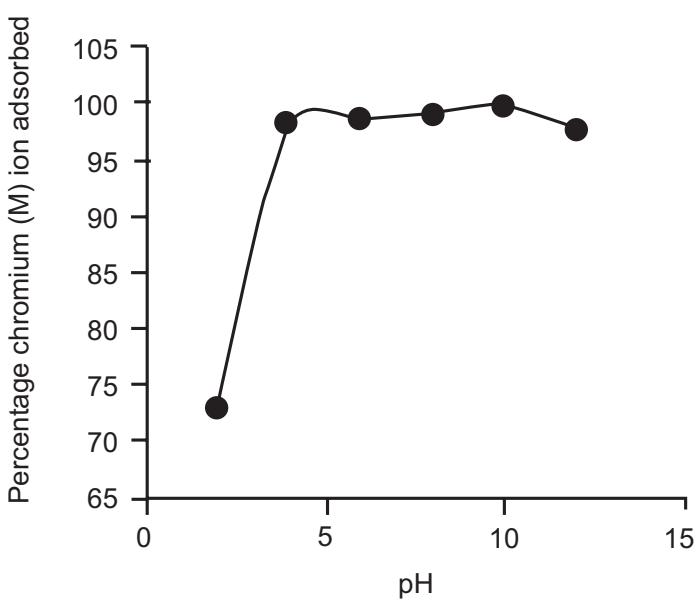

Fig. 1. Plot of percentage $\mathrm{Cr}$ (VI) ion adsorbed against $\mathrm{pH}$.

research by Lakhveer et al. (2012); Shim et al. (2007) and Kadiavelu and Namasivayam (2003).

Effect of temperature. The effect of temperature on the adsorption of $\mathrm{Cr}(\mathrm{VI})$ ions onto MRER was investigated for $60 \mathrm{mg} / \mathrm{L}$ of initial metal ion concentrations at 29, $40,50,60$ and $70^{\circ} \mathrm{C}$. It was observed that by increasing the temperature from 29 to $40{ }^{\circ} \mathrm{C}$, the percentage removal of $\mathrm{Cr}$ (VI) ions increased from 78.83 to $97.65 \%$. This showed that the adsorption process was endothermic in nature at this stage.

Further increase of the temperature from $40{ }^{\circ} \mathrm{C}$ to 50 , 60 and $70{ }^{\circ} \mathrm{C}$, showed that the percentage amount reduced gradually to $95.23,94.93$ and $90.73 \%$, respectively; implying that exothermic reaction occured at these temperatures and that interaction between the adsorbate and adsorbents reduced. This could also be as a result of decrease in the surface area of the adsorbent due to temperature increase and its impact on the structural alignment of the adsorbent (Fig. 2).

Effect of agitation time. The result for the time dependent experiment on the adsorption of chromium (VI) ions at $29^{\circ} \mathrm{C}$ is displayed in Fig. 3.

Agitation time effect on metal ion uptake was carried out by varying the agitation time (10 to $60 \mathrm{mins}$ ). The rate at which MRER adsorbed Cr (VI) ions increases steadily as the time variation increased. However, at 40 mins, the rate of metal ion uptake was maximum (98.37\%), which was observed to be the optimum adsorption time for the experiment. Further increase in agitation led to reduction in $\mathrm{Cr}(\mathrm{VI})$ ions. It could be

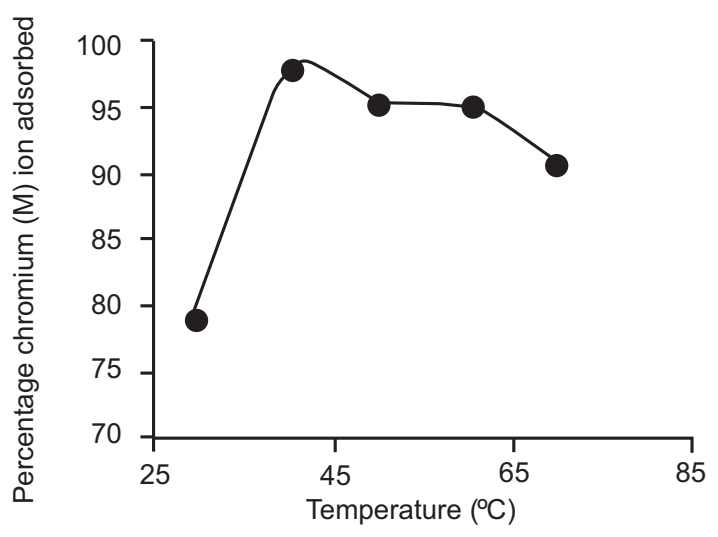

Fig. 2. Plot of percentage $\mathrm{Cr}$ (VI) ion adsorbed against temperature.

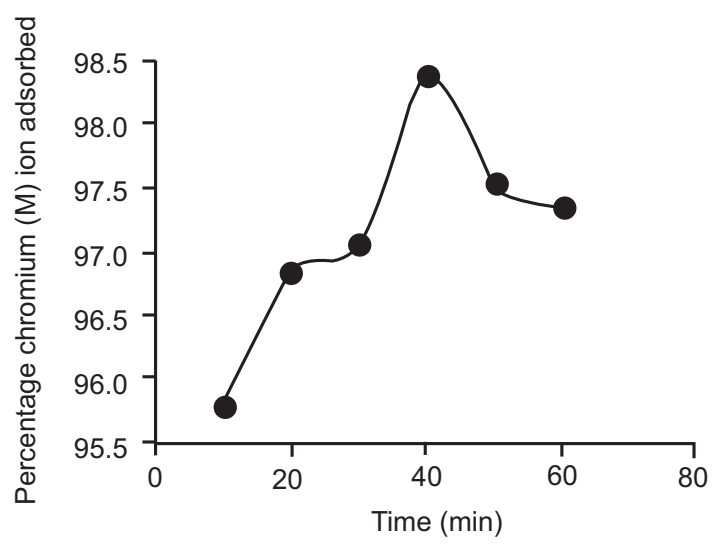

Fig. 3. Plot of percentage $\mathrm{Cr}$ (VI) ion adsorbed against time.

that available pores of MRER have been occupied by $\mathrm{Cr}$ (VI) ions before 40 mins.

Adsorption isotherm model. Adsorption isotherms describe the type of interaction that exist between sorbate and sorbents during an adsorption process when equilibrium state is attained (Shokoohi et al., 2009). Isotherm which describes the experimental data well was investigated by applying the equilibrium data evaluated at temperatures 29 to $70{ }^{\circ} \mathrm{C}$ to the linearized forms of Langmuir, Freundlich and Temkin models, (Ibezim-Ezeani and Anusiem, 2011; Langmuir, 1918; Freundlich, 1906)

Langmuir model assumes that sorption occurs in a homogeneous layer and can occur only at fixed sites and thus holding only one sorbate molecule at a time (monolayer). Hence, all sites are energetically equal 
and transmigration of sorbate in the plane of the layer do not occur (Boukhiar et al., 2008).

$$
\mathrm{q}_{\mathrm{e}}=\frac{1}{\mathrm{X}_{\mathrm{m}} \mathrm{b}}+\frac{\mathrm{C}_{\mathrm{e}}}{\mathrm{X}_{\mathrm{m}}} \ldots \ldots \cdots \cdots \cdots \cdots \cdots \cdots \cdots \cdots \cdots \cdots \cdots \cdots \cdots \cdots \cdots \cdots \cdots \cdots \cdots \cdots \cdots \cdots \cdots
$$

Freundlich isotherm applies to sorption on heterogeneous layer. It assumes that the ratio of the amount of solute adhere unto a certain mass of sorbent to the solute concentration in solution is not constant at varied concentration (Oubagaranadin et al., 2007).

$$
\text { In } \mathrm{q}_{\mathrm{e}}=\operatorname{In} \mathrm{K}_{\mathrm{F}}+\frac{1}{\mathrm{n}} \operatorname{In} \mathrm{C}_{\mathrm{e}}
$$

Temkin isotherm assumes that decrease in the heat of sorption is linear and the sorption is characterized by a uniform distribution of binding strength (Buasri et al., 2012).

$$
\mathrm{q}_{\mathrm{e}}=\frac{\mathrm{RT}}{\mathrm{b}_{\mathrm{T}}} \operatorname{In} \mathrm{K}_{\mathrm{T}}+\frac{\mathrm{RT}}{\mathrm{b}_{\mathrm{T}}} \operatorname{In} \mathrm{Ce}_{\mathrm{e}}
$$

where:

$\mathrm{b}, \mathrm{K}_{\mathrm{T}}$ and $\mathrm{K}_{\mathrm{F}}$ are Langmuir, Temkin and Freundlich isotherm constants, respectively. $1 / \mathrm{n}$ is the activity strength of adsorption in the sorption process having values between zero and one. $X_{m}, R, T$ are the monolayer adsorption capacity, universal gas constant and temperature, respectively. $\mathrm{C}_{\mathrm{e}}$ is the equilibrium concentration of the solute in the solution $(\mathrm{mol} / \mathrm{L}), \mathrm{q}_{\mathrm{e}}$ is the amount of solute adsorbed $(\mathrm{mol} / \mathrm{g})$ and $b_{\mathrm{T}}$ is related to the adsorption rate. The results for the adsorption isotherm models are presented in Fig. 3-6.

The correlation coefficient $\left(\mathrm{R}^{2}\right)$ values for the isotherm models explored in this study are presented in Table 1. Freundlich isotherm model gave the highest $\mathrm{R}^{2}$ values for the study and thus fitted the experimental data from the sorption process.

\begin{tabular}{|c|c|c|c|}
\hline $\operatorname{Temp}\left({ }^{\circ} \mathrm{C}\right)$ & Langmuir & Freundlich & Temkin \\
\hline 29 & 0.7095 & 0.9863 & 0.9396 \\
\hline 40 & 0.9186 & 0.9954 & 0.8547 \\
\hline 50 & 0.9010 & 0.9629 & 0.7659 \\
\hline 60 & 0.8953 & 0.9886 & 0.8509 \\
\hline 70 & 0.8852 & 0.9824 & 0.8454 \\
\hline
\end{tabular}

Table. 1 Comparison of coefficient of determination $\left(\mathrm{R}^{2}\right)$ for the Isotherms

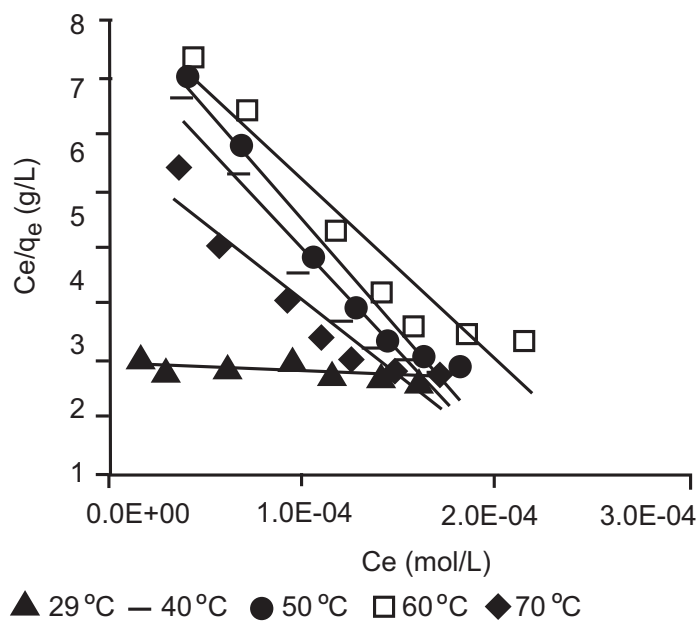

Fig. 4. Langmiur isotherms at different temperatures.

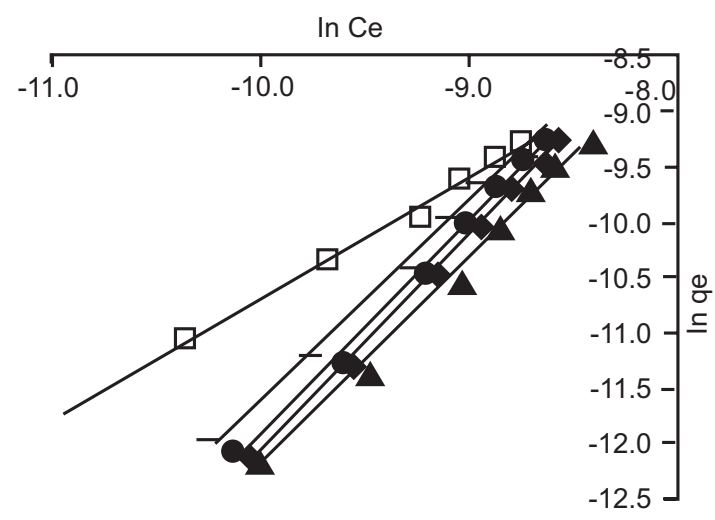

$29^{\circ} \mathrm{C} 40^{\circ} \mathrm{C}-50^{\circ} \mathrm{C}-60^{\circ} \mathrm{C}-70^{\circ} \mathrm{C}$

Fig. 5. Freundlich isotherms at different temperatures.

Furthermore, it implied that MRER possess a heterogenic surface with respect to Freundlich isotherm. In addition, $\mathrm{n}, 1 / \mathrm{n}, \mathrm{K}_{\mathrm{F}}$ and $\Delta \mathrm{G}$ at different temperatures studied were evaluated and their values are presented in Table 2 .

Plot of In KF versus 1/T produces a linear plot (Fig. 7); $\Delta \mathrm{H}$ and $\Delta \mathrm{S}$ were deduced from the slope and intercept using equations (6), while equation (7) was applied for resolving $\Delta \mathrm{G}$.

In $\mathrm{K}_{\mathrm{F}}=\frac{\Delta \mathrm{S}^{\mathrm{o}}}{\mathrm{R}}-\frac{\Delta \mathrm{H}^{\mathrm{o}}}{\mathrm{RT}} \cdots \cdots \cdots \cdots \cdots \cdots \cdots \cdots \cdots \cdots \cdots \cdots \cdots \cdots \cdots \cdots \cdots \cdots \cdots \cdots \cdots \cdots \cdots \cdots \cdots \cdots$

$\Delta \mathrm{G}=-\mathrm{RT}$ In $\mathrm{K}_{\mathrm{F}}$ 7 


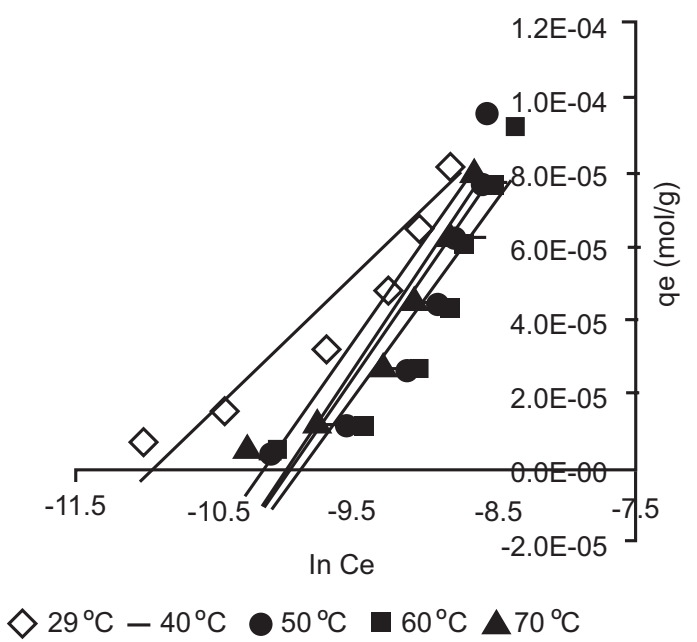

Fig. 6. Temkin isotherms at different temperatures.

Table 2. Freundlich constants and DG values at different temperatures.

\begin{tabular}{lllll}
\hline \hline & \multicolumn{4}{c}{ Freundlich constant } \\
\cline { 2 - 5 } Temp $\left({ }^{\circ} \mathrm{C}\right)$ & $\mathrm{n}$ & $1 / \mathrm{n}$ & $\mathrm{K}_{\mathrm{F}} \mathrm{mol} / \mathrm{g}$ & $\Delta \mathrm{G} \mathrm{kJ} / \mathrm{mol}$ \\
\hline 29 & 0.536 & 1.863 & 1299.19 & -18.001 \\
40 & 0.541 & 1.846 & 789.97 & -17.362 \\
50 & 0.542 & 1.844 & 772.70 & -17.860 \\
60 & 0.562 & 1.776 & 301.87 & -15.809 \\
70 & 0.581 & 1.720 & 288.47 & -16.154 \\
\hline \hline
\end{tabular}

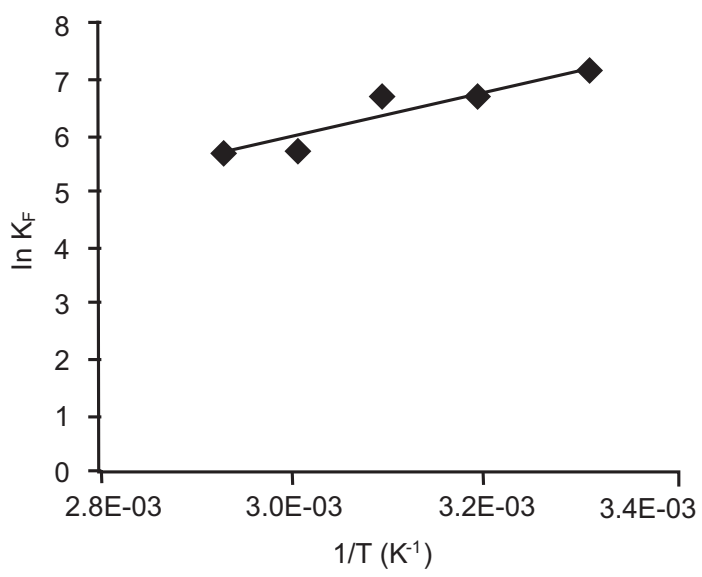

Fig. 7. Plot of $I n K_{F}$ against $1 / T$.

The $\Delta \mathrm{H}$ and $\Delta \mathrm{S}$ values as calculated from the slope and intercept of the graph in Fig. 7 are $-34.05414 \mathrm{~kJ} / \mathrm{mol}$, and $-52.7839 \mathrm{~J} / \mathrm{K} / \mathrm{mol}$, respectively. The $\Delta \mathrm{G}$ values evaluated at different temperatures are shown in Table 2 . The negative $\Delta \mathrm{H}$ values imply that exothermic sorption process occurred, while the negative $\Delta \mathrm{S}$ value indicates reduction in disorderliness of reaction system during the sorption of $\mathrm{Cr}(\mathrm{VI})$ ions. Also, negative $\Delta \mathrm{G}$ values signify the feasibility of the adsorption process at different temperatures studied.

Adsorption mechanism studies. The most likely mechanism (physisorption, particle diffusion or ion exchange) in which reaction followed for removal of $\mathrm{Cr}$ (VI) ions from an aqueous solution was investigated with the use of Dubinin-Radushkevich (DR) isotherm at different temperatures. The linear form of DR isotherm model is displayed in equation 8 :

$$
\text { In } \mathrm{q}_{\mathrm{e}}=\operatorname{In} \mathrm{q}_{\mathrm{D}}-\mathrm{B}_{\mathrm{D}} \varepsilon^{2}
$$

where:

$\mathrm{q}_{\mathrm{D}}=$ maximum ion adsorption capacity $(\mathrm{mol} / \mathrm{g})$ $\mathrm{B}_{\mathrm{D}}=\mathrm{DR}$ model constant $(\mathrm{KJ} / \mathrm{mol})$

$\varepsilon=$ Polanyi potential which is equivalent to RT In $(1+$ $1 / \mathrm{Ce}), \mathrm{R}(\mathrm{J} / \mathrm{mol} / \mathrm{K})$ is the universal gas constant and $\mathrm{T}$ $(\mathrm{K})$ is temperature. $\mathrm{B}_{\mathrm{D}}$ is related to the mean free energy $\mathrm{E}$, of sorption per mole of metal ion through equation 9:

$$
\mathrm{E}=\frac{1}{\sqrt{2 \mathrm{~B}_{\mathrm{D}}}} \cdots \cdots \cdots \cdots \cdots \cdots \cdots \cdots \cdots \cdots \cdots \cdots \cdots \cdots \cdots \cdots \cdots \cdots \cdots \cdots \cdots \cdots \cdots \cdots \cdots \cdots \cdots \cdots
$$

Plot of In $\mathrm{q}_{\mathrm{e}}$ against $\varepsilon^{2}$ (Fig. 8) gave linear graph.

The slope and intercept were used to deduce the values of $B_{D}$ and $q_{D}$ while the values of $E$ were calculated by

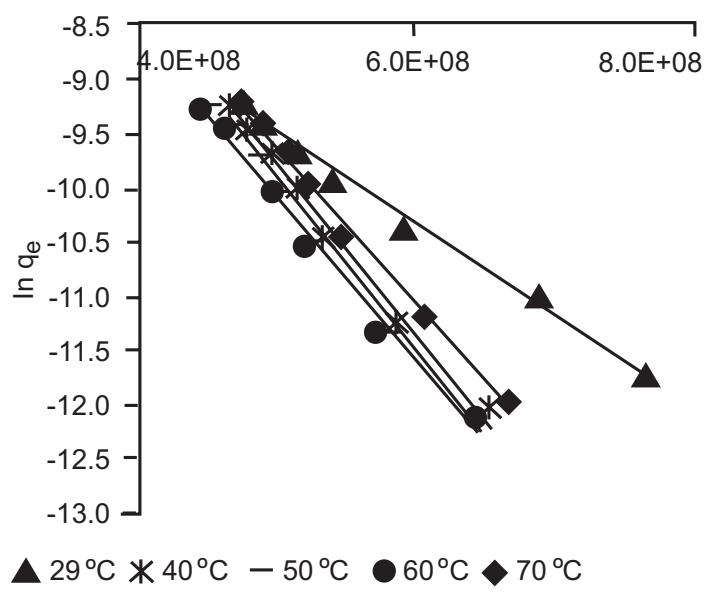

Fig. 8. Plot of Dubinin-Radushkevich isotherm model at varying temperature. 
Table. 3 Dubinin-Radushkevich constants, linear equations and $\mathrm{R}^{2}$ values

\begin{tabular}{llllll}
\hline \hline Temp $\left({ }^{\circ} \mathrm{C}\right)$ & Linear equation & $\mathrm{B}_{\mathrm{D}}\left(\mathrm{mol}^{2} / \mathrm{J}^{2}\right)$ & $\mathrm{q}_{\mathrm{D}}(\mathrm{mol} / \mathrm{g})$ & $\mathrm{E}(\mathrm{kJ} / \mathrm{mol})$ & $\mathrm{R}^{2}$ \\
\hline 29 & $\mathrm{y}=-1.563 \mathrm{E}-08 \times-1.6097$ & $1.563 \mathrm{E}-08$ & 0.1999 & 5.66 & 0.9905 \\
40 & $\mathrm{y}=-1.560 \mathrm{E}-08 \times-1.9859$ & $1.560 \mathrm{E}-08$ & 0.1373 & 5.66 & 0.9928 \\
50 & $\mathrm{y}=-1.557 \mathrm{E}-08 \times-2.1298$ & $1.557 \mathrm{E}-08$ & 0.1189 & 5.67 & 0.9579 \\
60 & $\mathrm{y}=-1.520 \mathrm{E}-08 \times-2.5007$ & $1.520 \mathrm{E}-08$ & 0.0820 & 5.74 & 0.9948 \\
70 & $\mathrm{y}=-1.436 \mathrm{E}-08 \times-2.4761$ & $1.436 \mathrm{E}-08$ & 0.0841 & 5.90 & 0.9794 \\
\hline \hline
\end{tabular}

inserting the value of $B_{D}$ into equation (9). Table 3 contains the $\mathrm{E}$ values at different temperatures studied. However, it was observed that the $\mathrm{E}$ values were less than $8 \mathrm{~kJ} / \mathrm{mol}$, which suggest that physisorption is the pathway which the reaction process followed.

Adsorption kinetic study. The kinetics of $\mathrm{Cr}$ (VI) ion adsorption by MRER was investigated by varying the concentration of ions adsorbed at different tempretures and time intervals. The kinetic data were analysed by applying pseudo-first order, pseudo-second order, Elovich and Intraparticle diffusion models to achieve a more reliable result and good understanding of the adsorption dynamic behaviour. Linear equations of the models are presented below.

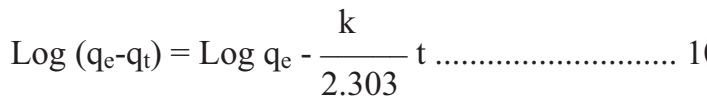

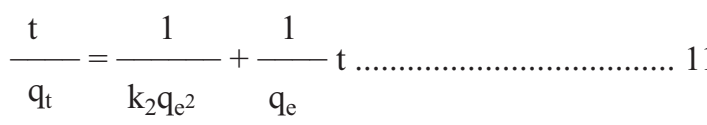

$$
\begin{aligned}
& \mathrm{q}_{\mathrm{t}}=\frac{1}{\beta} \ln (\alpha \beta)+\frac{1}{\beta} \ln (\mathrm{t}) \\
& \mathrm{q}_{\mathrm{t}}=K_{\mathrm{p}} \mathrm{t}^{1 / 2}+\mathrm{C}
\end{aligned}
$$

The plots which were evaluated from the linear equations and from the experimental data are presented in Fig. 912. The corresponding $R^{2}$ values are presented in Table 4.

From the analysis, its was observed that the values of $\mathrm{R}^{2}$ for pseudo-second order model are higher than those of other models. Therefore, the kinetic adsorption data fits well to the pseudo-second order model. The pseudosecond order rate constant $\left(\mathrm{k}_{2}\right)$ and $\mathrm{q}_{\mathrm{e}}$ were determined from the slope and intercept of the plots. A plot of In $\mathrm{k}_{2}$ against $1 / \mathrm{T}$ at various temperatures was plotted

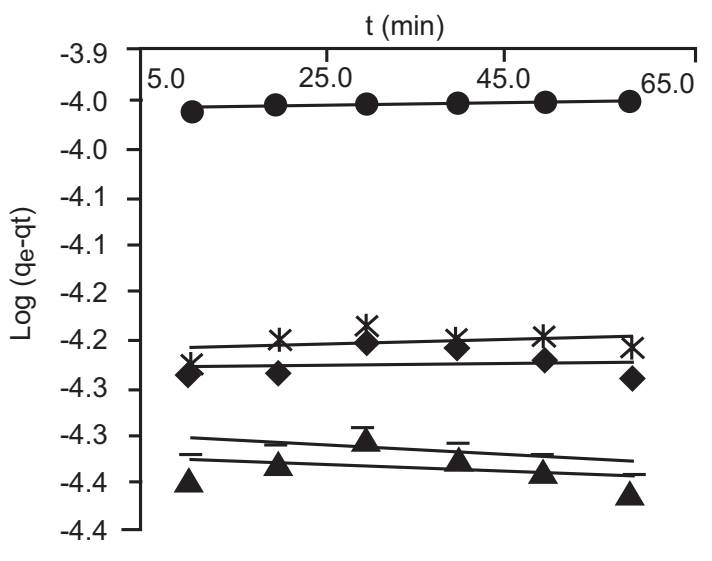

$29^{\circ} \mathrm{C} * 40^{\circ} \mathrm{C} 50^{\circ} \mathrm{C}-60^{\circ} \mathrm{C} \triangle 70^{\circ} \mathrm{C}$

Fig. 9. Plot of first order kinetic model at varying temperature.

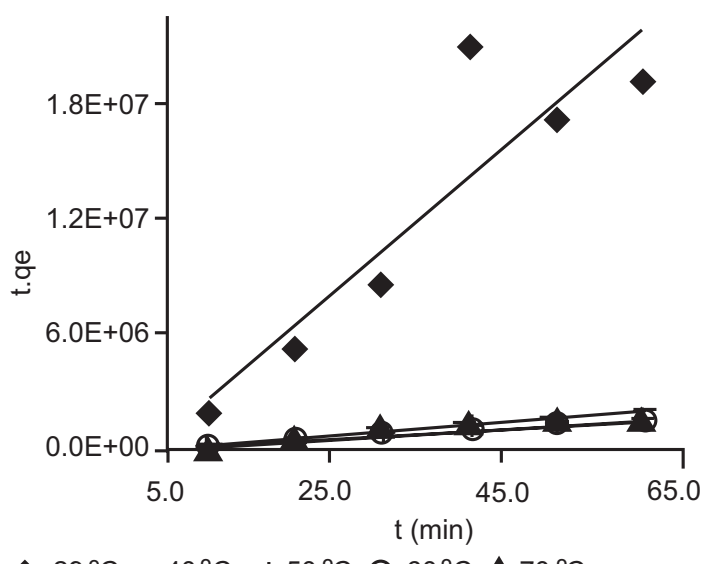

$29^{\circ} \mathrm{C}-40^{\circ} \mathrm{C}+50^{\circ} \mathrm{C}$ O $60^{\circ} \mathrm{C} \triangle 70^{\circ} \mathrm{C}$

Fig. 10. Plot of second order kinetic model at varying temperature.

(Fig. 13) and from the plot, the pre exponential factor (A) and activation energy (Ea) was determined with regards to the slope and intercept. The pre exponential factor was observed to be $3.2554 \times 105 \mathrm{~g} / \mathrm{mol} / \mathrm{min}$ while the activation energy was $796.290 \mathrm{~kJ} / \mathrm{mol}$. 


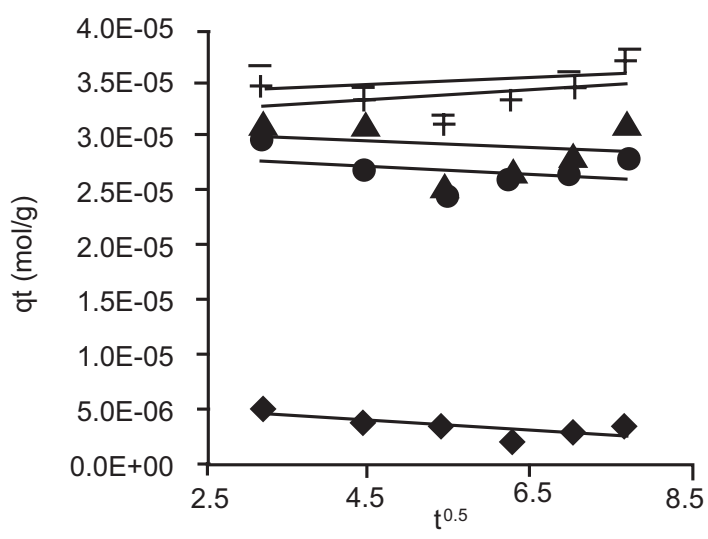

$29^{\circ} \mathrm{C}-40^{\circ} \mathrm{C} \triangle 50^{\circ} \mathrm{C}+60^{\circ} \mathrm{C}-70^{\circ} \mathrm{C}$

Fig. 11. Plot of intraparticle diffusion kinetic model at varying temperature.

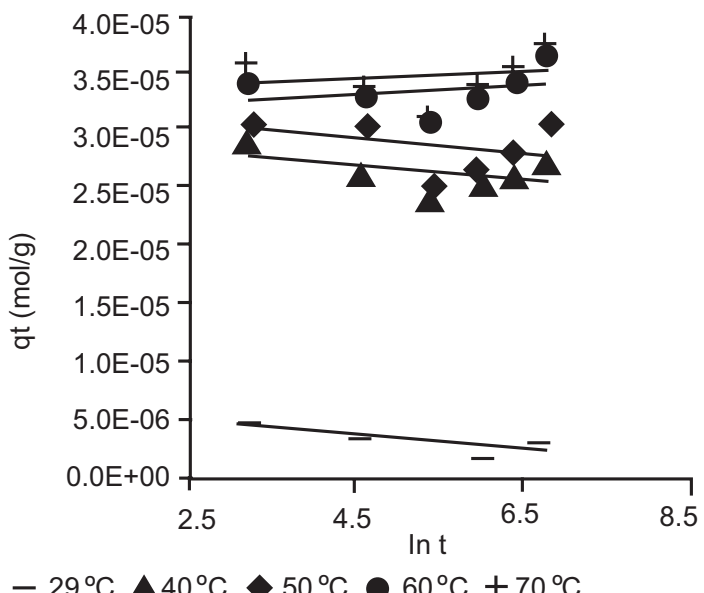

Fig. 12. Plot of Elovich kinetic model at varying temperature.

Table 4. Comparison of coefficient of determination $\left(\mathrm{R}^{2}\right)$ for the Isotherms

\begin{tabular}{lllll}
\hline \hline $\begin{array}{l}\text { Temp } \\
\left({ }^{\circ} \mathrm{C}\right)\end{array}$ & $\begin{array}{l}\text { Pseudo- } \\
\text { first } \\
\text { order }\end{array}$ & $\begin{array}{l}\text { Pseudo- } \\
\text { second } \\
\text { order }\end{array}$ & $\begin{array}{l}\text { Intraparticle } \\
\text { diffusion }\end{array}$ & Elovich \\
\hline 302 & 0.4868 & 0.8130 & 0.5775 & 0.6568 \\
313 & 0.0834 & 0.9832 & 0.1523 & 0.2504 \\
323 & 0.0231 & 0.9773 & 0.0592 & 0.1090 \\
333 & 0.2497 & 0.9773 & 0.1514 & 0.0781 \\
343 & 0.1481 & 0.9857 & 0.0710 & 0.0221 \\
\hline \hline
\end{tabular}

Scanning electron microscope gives details of the surface properties and morphology of the samples. Particle size used for this analysis was $400 \mu \mathrm{m}$ for all samples. Figure 14(a-c) displays the SEM images for unmodified and

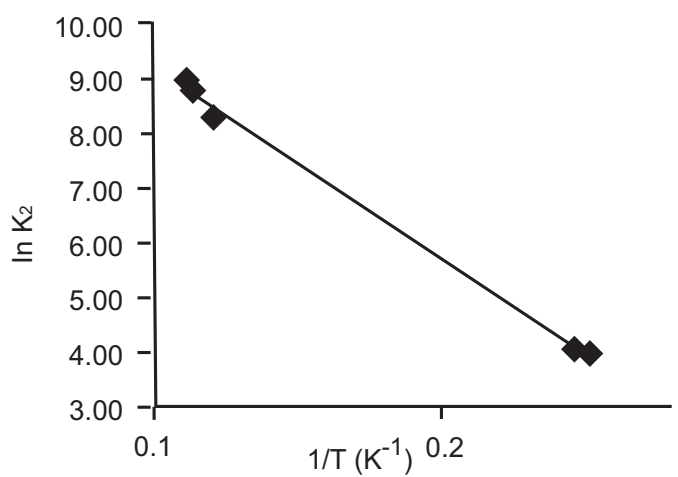

Fig. 13. Plot of In $K_{2}$ against $1 / T$.

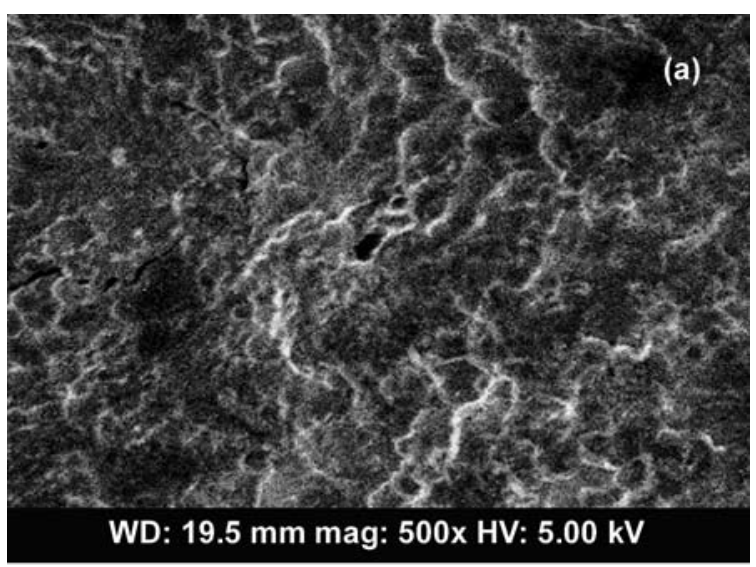

Fig. 14(a). SEM image of unmodified red onion skin extract..

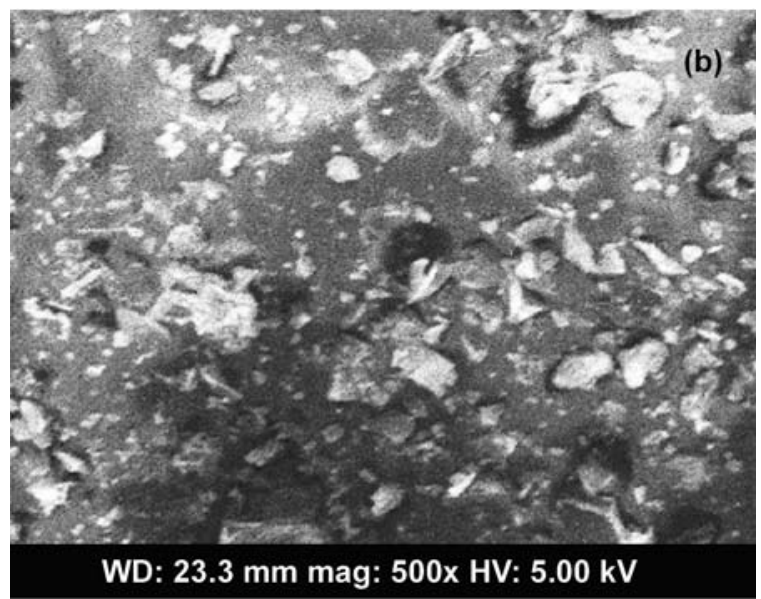

Fig. 14(b). SEM image of MRER. 


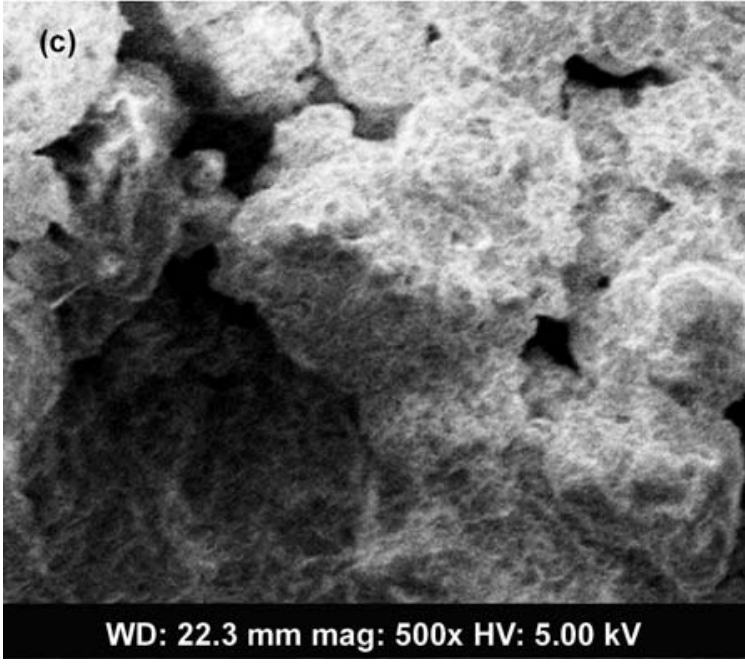

Fig. 14(c). SEM image of MRER after adsorption of $60 \mathrm{mg} / \mathrm{L} \mathrm{Cr}$ (VI) ions.

maleic acid modified red onion skin extract resins. Figure 14(a) shows that the unmodified red onion skin extract possess smooth surface structure which implies that it has a smaller surface area and its pores where adsorption of metal ions could take place are few. Figure 14(b), showed that the surface structure of the adsorbents changed on modification with maleic acid. It can be observed that the surface property of MRER (Fig 14 b) possess irregular shapes implying that the resin have large surface area as compared to the unmodified extract resin and has more pore spaces for adsorption of metal ion. Figure 14(c) showed MRER after adsorption of metal ions. Observation shows that some of its pores have closed up due to the fact that the pores now contain metal ions thus, making it relatively smooth as compared to the unadsorbed MRER.

\section{Conclusion}

Chemical treatment of red onion skin extract with maleic acid, increased its efficiency towards adsorption of $\mathrm{Cr}$ (VI) ion from aqueous solution. The adsorption capacity studies showed that agitation time, $\mathrm{pH}$ and temperature affected the rate at which $\mathrm{Cr}$ (VI) ion was adsorbed from aqueous solution by MRER. Thermodynamics studies conducted at temperatures 29 to $70{ }^{\circ} \mathrm{C}$ showed that Freundlich isotherm model gave best fit for the experimental data; indicating that MRER possesses a heterogeneous surface; while from the kinetic studies, it was observed that pseudo-second order kinetic best described the kinetic reaction. However, the adsorption process was observed to be feasible with respect to the negative $\Delta \mathrm{G}(\mathrm{kJ} / \mathrm{mol})$ values at all temperatures following the sequence: $-18.001\left(29^{\circ} \mathrm{C}\right),-17.362(40$ $\left.{ }^{\circ} \mathrm{C}\right),-17.860\left(50{ }^{\circ} \mathrm{C}\right),-15.809\left(60{ }^{\circ} \mathrm{C}\right)$ and $-16.154(70$ $\left.{ }^{\circ} \mathrm{C}\right)$. The results obtained from fitting the experimental data into the Dubinin-Raduskevich isotherm model showed that the major sorption pathway for the sorption process is physisorption. The SEM analyses of MRER revealed that the synthesized resin possesses larger and more active pore spaces than the unmodified red onion skin extract sample making it possible for adsorption of metal ion in aqueous solution. The synthesized adsorbent can be further used for removal of other heavy metals.

\section{Acknowledgement}

Special thanks to Dr. Ikodiya Orji, Department of Pure and Industrial Chemistry, University of Port Harcourt, Rivers State Nigeria for her contribution during the experimental section of this research.

Conflict of Interest. The authors declare no conflict of interest

\section{References}

Abayomi, L.A., Terry, L.A. 2009. Implication of spatial and temporal changes in concentration of pyruvate and glucose in onion (Allium cepa .L.) bulb during controlled atmosphere storage. Journal of Science Food and Agriculture, 8: 683-687.

Bailey, S.E., Olin, T.J., Bricka, R.M., Adrian, D.D. 1999. A review of potentially low cost sorbents for heavy metals. Water Research, 33: 2469-2479.

Bose, B., Hemantaranjan, A. 2005. Developments in Physiology, Biochemistry and Molecular Biology of Plants. pp. 105. New Delhi, India. New India publishing Agency.

Buasri, A., Chaiyut, N., Tapany, K., Jaroensin, S., Panphrom, S. 2012. Biosorption of heavy metals from aqueous solution using water hyacinth as a low cost biosorbent Civil and Environmental Research, 2: 17-24.

Cao, J., Wu, Y., Jin, Y., Yilihan, P., Huang, W. 2014. Response surface Methodology approach for optimization of the removal of chromium (VI) by $\mathrm{NH}_{2}-\mathrm{MCM}-41$. Journal of Taiwan Institute and Chemical Engineering, 45: 860-868.

Cha, D., Song, J., San, D. 1997. Treatment technologies. 
Water Environment Research, 69: 676-689.

Chowdhury, A., Bhowal, A., Siddhartha, Datta. 2012. Equilibrium, thermodynamic and kinetic studies for removal of copper (II) from aqueous solution by onion and garlic skin. Water Journal, 4: 37-51.

Downes, K., Chope, G.A., Terry, L.A. 2010. Post-harvest application of ethylene and 1-methycyclopropene either before or after curing effects onion (Allium сера .L.) bulb quality during long term cold storage. Post-harvest Biological Technology, 55: 36-44.

Freundlich. H.M.F. 1906. Over the adsorption in solution. Journal of Physical Chemistry, 57, 385-470.

Gao, H., Liu, Y., Zeng, G.,Xu, W., Li, T., Xia, W. 2008. Characterization of $\mathrm{Cr}$ (VI) removal from aqueous solutions by a surplus agriculture waste-rice straw. Journal of Hazardous Materials, 150: 446-452.

Garba, Z.N., Afidah, A.R., Bello, B.Z. 2015. Optimization of preparation conditions for activated carbon from Brachystegia eurycoma seed hulls; a new precursor using central composite design. Journal of Environmental Chemistry and Engineering, 3: 2892-2899.

Garba, Z.N., Afidah, A.R. 2014. Process optimization of $\mathrm{K}_{2} \mathrm{C}_{2} \mathrm{O}_{4}$ activated carbon from Prosopis africana seed hulls using response surface methodology. Journal of Analytical and Applied Pyrolysis, 107: 306-312.

Garba, Z.N., Afidah, A.R., Hamza S.A. 2014. Potential of Borassus aethiopium shells as precursor for activated carbon preparation by physico-chemical activation; optimization, equilibrium and kinetic studies. Journal of Environmental Chemistry and Engineering, 2: 1423-1433.

Hamead, B., Ahmand, A. 2009. Batch adsorption of methylene blue from aqueous solution by garlic peel an agricultural waste biomass. Journal of Hazardous Materials, 164: 870-875.

Hwang, E.K., Lee, Y.H., Kim, H.D. 2008. Dyeing, fastness and deodorizing properties of cotton, silk and wool fabrics dyed with gardenia, coffee sludge, Cassia tora L, and pomegranate extracts. Fibers and Polymers, 9: 334-340.

Ibezim-Ezeani, M.U., Ikodiya, Orji. 2017. Sorption studies on the remediation of cadmium (II) ions contaminated water using succinic acid modified red onion skin extracts. International Journal of Innovative Research and Development, 6: 117-127.

Ibezim-Ezeani, M.U., Anusiem, A.C.I. 2011. Thermodynamics of the adsorption of palmitate and laurate soaps onto some metal ore surfaces in aqueous media, African Journal of Pure and Applied Chemistry, 6: 49-54.

Igwe, J.C., Nwokennayu, E.C., Abia, A.A. 2005. The role of $\mathrm{pH}$ in Heavy metal detorification by biosorption from aqueous solutions containing chelating agents. African Journal of Biotechnology, 4: 1109-1112

Ikodiya, O., Millicent, U., Ibezim-Ezeani, M.U., Onyewuchi, A. 2016. Utilization of red onion skin extract for remediation of lead (II) and cadmium (II) ions from aqueous solution. International Journal of Enhanced Research in Science, Technology and Engineering, 5: 283-291.

Johns, M.M., Marshall, W.E., Toles, C.A. 1998. Agricultural by products as granular activated carbon for Adsorbing dissolved metals and organics. Journal of Chemical Technology and Biotechnology, 77: 131-140.

Kadiavelu, K., Namasivayam, C. 2003. Activated carbon from coconut coir pith as metal adsorbent. Adsorption of $\mathrm{Cd}$ (II) from aqueous solution. Advances in Environmental Research, 7: 471-478.

Kannan, M., Murugavel, N. 2007. Column studies on the removal of dyes Rhodamine- $\mathrm{B}$, congo red acid violet by adsorption on various adsorbents, EJEAF Chem, 6: 1860-1868

Kumara, A. 2013. Banana peel: A green solution for metal removal from contaminated waters. Korean Journal of Environmental Agriculture, 32: 108-116.

Kumar, U., Bandopadhayay, M. 2006. Fixed bed column study for Cd (II) removal from waste water using treated rice husk. Journal of Hazardous Materials, 129: 253-259.

Lakhveer, S., Anwan, A., Zularisam, A. 2012. Equilibrium, thermodynamic and kinetic studies for removal of chromium from aqueous solution by grafted copolymer. International Journal of Civil Engineering and Geo-environmental, 3: 57 61.

Langmuir, T. 1918. The adsorption of gases on plane surfaces of glass, mica and platinum. Journal of American Chemical Chemistry, 40: 1362-1403.

Lindahl, S., Liu, J., Khan, S., Nordberg-Karlsson, E., Tuner, C. 2013. An online method for pressurized hot water extraction and enzymatic hydrolysis of quercetin glycosides from onion. Analytical Chemistry, 785: 50-59.

Marshall, W.E., Akin, D.E., Wartelle, L.H., Annis, P.A. 2007. Citric acid treatment of flax, cotton and blended nonwoven mats for copper ion absorption. 
Industrial crops and products, 26: 8-13.

Marshall, W.E., Wartelle, L.H. 2003. Acid recycling to optimize citric acid-modified soybean hull production. Industrial Crops and Products, 18: 177-182.

Masoud, I. 2013. Removal of Fe (II) from aqueous solution using pomegranate peel carbon, equilibrium and kinetic studies. International Journal of Industrial Chemistry, 4: 19.

Misra, S., Mani, D. 2009. Soil Pollution. pp 29-59, S.B. Nangia APH Publishing Corporation, New Delhi, India.

Mohamadi, M., Ghaemi, A., Torab-Mostaedi, M., Asadollahzadeh, M., Hemmati, A. 2015. Adsorption of Cadmium (II) and nickel (II) ion dolomite powder. Desalination of Water Treatment, 53: 149157.

Mohammed, M.A., Ibralum, A., Shitu, A. 2014. Batch removal of hazardous safranin-o in waste water using pineapple peel as an agricultural waste based adsorbent. International Journal of Environmental Monitoring and Analysis, 3: 128-133.

Mohan, D., Singh, K.P., Sing, V.K. 2008. Waste water treatment using low-cost activated carbon derived from agricultural by products-a case study. Journal of Hazardeus Materials, 152: 1045-1053.

Nada, A.A.M.A.A., Mahdy, A.A., EI-Gendy, A.A. 2009. Spectroscopy and chemical studies of cation exchangers from corncob. Bioresources, 4: $1077-$ 1031.

Oancea, S., Davis, M., Draghici, O. 2013. pH and thermal stability of anthocyanin-based optimized of Romanian red onion cultivars. Czech. Journal of Food Science, 31: 283-291.

Ogali, R.E., Akarnata, O., Aririguzo, V.O. 2008. Removal of some metal ions from aqueous solution using Orange mesorcarp. African Journal of Biotechnology, 7: 3073-3076.

Oubagaranadin, J., Murth, Y., Rao, P. 2007. Applicability of three parameters isotherm model for the adsorption of mercury on fuller's earth and activated carbon. Indian Chemical Engineer, 49: 196-204.

Ralkwar, M.K., Kumar, P., Singh, M., Singh, A. 2008. Toxic effect of heavy metals in livestock health Veterinary World. 1: 28-30.
Roldan, E., Sa' nchez-Moreno, C., de Ancos, B., Cano, M. P. 2008. Characteristics of onion (Allium cepa) by products as food ingredients with antioxidant and antibrowning properties. Food Chemistry, 108: 907-916.

Sahmoune, M.N., Louhab, K., Boukhair, A., Addad, J., Barr, S. 2008. Kinetic and equilibrium models for the biosorption of Cr (III) on Streptomyces rimosus. Research Journal of Applied Science, 3: 294-300.

Salak, F., Daneshvar, S., Abedi, J., Farakawa, K. 2013. Adding value to onion (Allium cepa) waste by subcritical water treatment. Fuel Processing Technology, 112: 86-92.

Shim, E.W., Karthikeyan, K.G., Tshabalala, M.A. 2007. Adsorption mechanism of cadmium on Juniper bark and wood. Bioresource Technology, 98: 588-594.

Shokoohi, R., Saghi, M., Ghafari, H., Had, M. 2009. Biosorption of iron from aqueous solution by dried biomass of activated sludge. Iranian Journal of Environmental Health Science and Engineering, 2: 107-114.

Slimestad, R., Fossen, T., Vagen, I.M. 2007. Onions: A source of unique dietary flavonoids. Journal of Agriculture and Food Chemistry, 55: 10067-10080.

Thanh, N., Nhung, H. 2009. Cellulose modified with citric acid and its absorption of $\mathrm{Pb}^{2+}$ and $\mathrm{Cd}^{2+}$ ions. In Proceedings of the $13^{\text {th }}$ International Electronic Conference of Synthetic Organic Chemistry; Science Forum Electronic Conference Series 13, F003.

Yu, B., Zhang, Y., Shukla, A., Shukla, S., Dorris, K.L. 2001. The removal of heavy metal from aqueous solution by sawdust adsorption-removal of lead and comparison of adsorption with Koper. Journal of Hazardous Materials, 84: 83-94.

Zaharaddeen, N.G., Nkole, I.U., Amina, K.A. 2016. Evaluation of optimum adsorption conditions for $\mathrm{Ni}$ (II) and Cd (II) removal from aqueous solution by modified plantain peal (MPP). Journal of Basic and Applied science, 5: 170-179.

Zvinowanda, C.M., Okonkwo, J.O., Shabalala, P.N., Agyei, N.M. 2009. A novel adsorbent for heavy metal. Journal of Environmental Science and Technology, 6: 425-434. 